\title{
Support for Physical Sciences and Engineering
}

This Public AfFairs Forum feature is based on a presentation by Mildred $S$. Dresselhaus, director of the U.S. Department of Energy (DOE) Office of Science, given at the 2000 Materials Research Society Fall Meeting in Boston on November 28, 2000.

One of the questions we address in any federally funded activity is how much research is enough. We cannot increase research funding arbitrarily, but we must have a goal. In 1993, the National Academy of Science Committee on Science, Engineering, and Public Policy (COSEPUP) published a report, "Science, Technology, and the Federal Government: National Goals for a New Era," that provides a guideline for identifying what constitutes an appropriate level of funding. The report concludes that since it has been impossible to predict which fields of science will ultimately contribute new technologies, the United States must be among the leaders in all major fields of science and engineering in order to take advantage of an invention or discovery made here or elsewhere. It illustrates the need for this positioning by noting that we could not have been so successful in the semiconductor and biotechnology industries were it not for our strengths in solidstate physics and molecular biology.

When I became director of the Office of Science at the Department of Energy (DOE) and looked over our portfolio, it became obvious to me that we cannot be the leader in all subfields of materials science from where we are now, but we have to be among the leaders. I am very comfortable with that goal because it creates a healthy competition with other countries that also want to be among the leaders that will benefit science generally. I am concerned, however, that without increased funding, our leadership position will slip, and there are some indicators that this may be happening already.

The American Physical Society provided statistics on submissions to Physical Review and Physical Review Letters, two leading U.S. peer-reviewed journals in physics. Figure 1 shows that the Western European contribution to these top U.S. journals is now larger than the U.S. contribution, and the contribution from the remainder of the world is larger than either of these two and growing at a rapid rate. The number of articles submitted by U.S. authors has remained fairly constant over the past decade. This is related to the funding situation and shows that the U.S. influence is declining seriously in the world of physics, particularly because U.S. authors publish mostly in U.S. journals, while non-U.S. authors are likely also to publish in journals of their own countries.

There is also reason for some specific concern about materials science. In a recent COSEPUP report, a panel of expert researchers in, and users of, materials science concluded that "the United States is among the world leaders in all subfields of materials science and engineering research and is the leader in some subfields, although not in the field as a whole." The report also said, however, that this U.S. position is at risk because of insufficient funding to modernize facilities or build new ones, and that "...a general area of U.S. weakness is in materials synthesis and processing. Increasingly, U.S. researchers must rely on specialty materials suppliers in Europe and Japan for bulk crystals and other specialty materials."

The COSEPUP report and the statistics from Physical Review and Physical Review Letters, among others, has helped me to think strategically about what the Office of Science should be doing. With $43 \%$ of federal support for the physical sciences, DOE is the dominant funding agency of the physical sciences and engineering in the United States. A large part of my office's responsibilities is also the construction and operation of research facilities. These include synchrotron light sources, neutron sources, and other user facilities throughout the country, serving over 15,000 users per year. State-of-theart facilities are expensive to build, to maintain, and to service, but are neces-

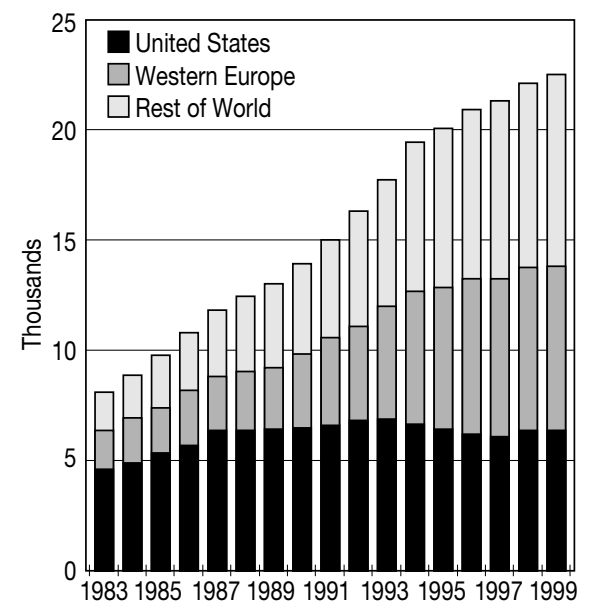

Figure 1. The American Institute of Physics statistics from Physical Review and Physical Review Letters on submissions by location. sary to allow researchers to work at the cutting edge. We must continue to provide these facilities to meet the demands of the science we are doing. The facilities budget will have to increase to address the increasing complexities of the facilities and increased number of users, but within a flat budget this can only occur at the expense of funding for research. Unfortunately, this means funding for the physical sciences, and the Office of Science has not kept pace with increases in other areas.

In 1970, the life sciences and physical sciences each received about $40 \%$ of the federal budget for research. However, in recent years, federal funding for the life sciences-exemplified by funding for the National Institutes of Health (NIH)-has increased by almost a factor of two, while funding for physical sciences and the Office of Science stagnated, even as both the cost of research and the cost of building and operating facilities has increased. This imbalance in resources between the physical sciences and the life sciences has recently become of concern to many thoughtful members of the scientific community, and to members of Congress as well. David Baltimore and Harold Varmus, both Nobel Laureates in medicine, have written on this issue. To quote Varmus, "Senators Bond and Mikulski have proposed to double the budget of the NSF over five years. This admirable effort should be vigorously supported and extended to include the DOE's Office of Science, which funds half of all research in the physical sciences and maintains the national laboratories that are central to biomedicine." Last year, this awareness led to vocal and effective support for the Office of Science. Presidents of major research universities and others contacted both the Presidential administration and Congress, and 97 representatives and 36 senators wrote letters supporting the Office of Science. This resulted in the first significant increase in funding for our programs since the termination of the SSC in 1993. Over half of that increase, however, went to construction of the Spallation Neutron Source and for upgrades and increased utilization of existing user facilities. We also had significant increases in nanoscience, in the life sciences, and for a program of computational modeling to support all of our research areas. Nevertheless, some areas of research had a funding decrease in constant dollars.

Next year, we have a commitment to continue building the Spallation Neutron 

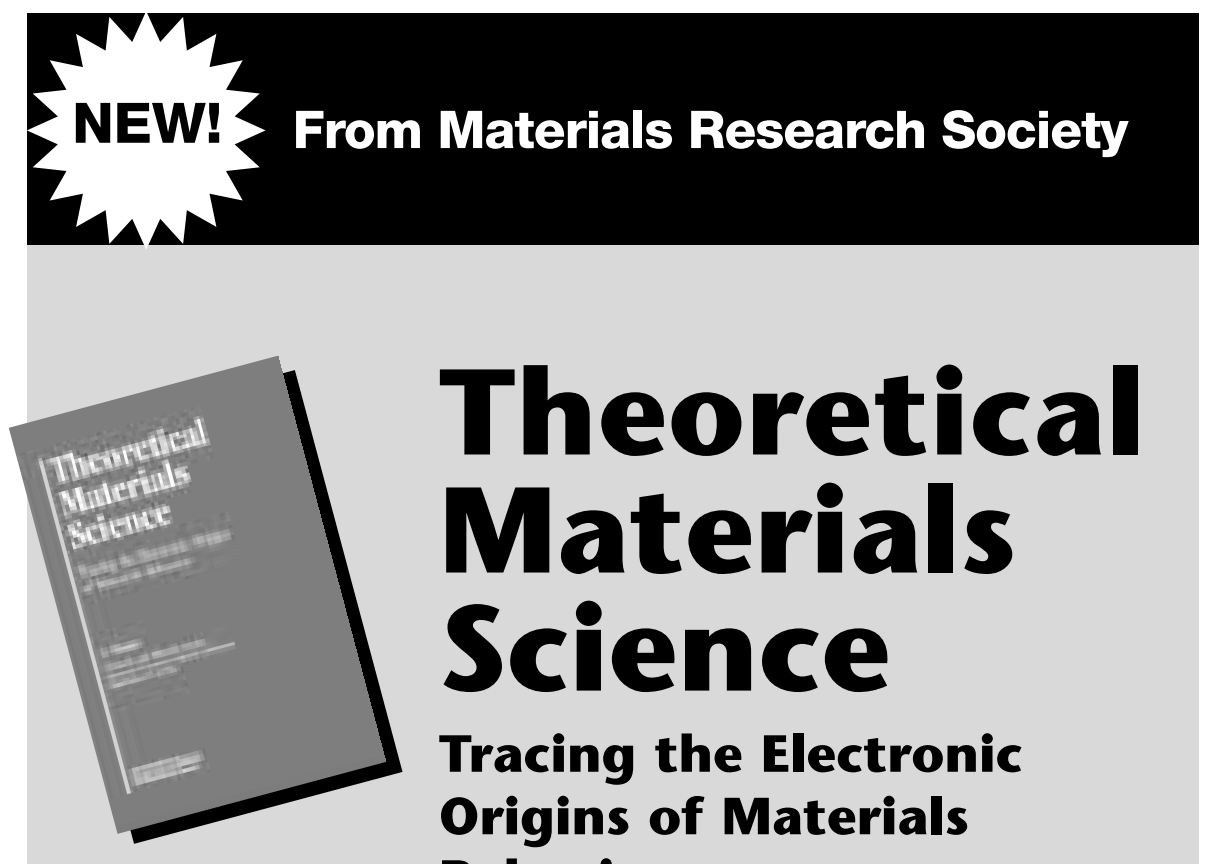

\section{Theoretical Materials Science}

\section{Tracing the Electronic Origins of Materials Behavior}

\section{by A. Gonis}

The primary goal of a materials scientist is a predictive understanding of materials properties, and that requires a clear picture of the role played by electrons in determining the materials behavior. Only then can one hope to design and build new materials with desired physical, chemical and engineering characteristics. Present-day research into this subject is carried out on the basis of quantum mechanics, through solution of the so-called single-particle Schrödinger equation that describes the behavior of electrons in a solid. This new volume from Antonios Gonis attempts to describe one formal approach to solving the Schrödinger equation developed within the framework of multiple scattering theory (MST). With 24 chapters and 1063 pages, the volume offers a comprehensive and welcome entre to the field of electronic structure of solids and should serve as a treatise for advanced undergraduates, graduate students and researchers in the field. Topics include: concepts and formalism; periodic solids and impurities; substitutional alloys; surfaces and interfaces; transport; phonons and photons; and formal Green-function theory. 2000, hardcover, 1063 pages.

ISBN: 1-55899-540-4 Code: TMS-GF

\section{$\$ 73$}

$\$ 84$

$\$ 98$
MRS Member

USA List

Non-USA List

\section{ORDER FROM:}

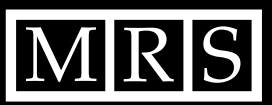

Customer Services 506 Keystone Drive Warrendale, PA 15086 USA Tel: $724-779-3003$ Fax: 724-779-8313 E-mail: info@mrs.org www.mrs.org/publications/
Source, which will restore the leadership in neutron science. We also expect to continue our commitment to nanotechnology, to scientific modeling, and to support for an ever-increasing number of users at our facilities. We also must restore those fields, such as high-energy and nuclear physics, that did not benefit from increased support this year, but where research opportunities are outstanding. To do this, we must make the case to Congress for additional resources, and we need to make that case based on excellence in science, and benefit to the United States. Since I took my position at the Office of Science in August, I have made many visits to Congress, and I find that both the members and their staffs are very interested in science. They like to hear what we have to say about the exciting things now occurring in science, and they like to hear science made simple so that they can understand what it is that we do, why we do it, and how it benefits the country.

MiLDRED S. DRESSELHAUS

Mildred S. Dresselhaus is the director of the U.S. Department of Energy (DOE) Office of Science.

Access the Materials
Research Society Public
Affairs Website for links
to Policies in Science
and Technology

Links include:
V FYl-by Audrey Leath and
Richard Jones, American
Institute of Physics
$\nabla$ Centre for Policy Research
on Science and Technology
$\nabla$ Parliamentary Office of
Science and Technology (U.K.)
$\nabla$ The Rand Corporation
$\nabla$ Technology and Innovation
Policy Information Map

